\title{
The venom composition of the parasitic wasp Chelonus inanitus resolved by combined expressed sequence tags analysis and proteomic approach
}

\author{
Bruno Vincent ${ }^{1}$, Martha Kaeslin², Thomas Roth², Manfred Heller ${ }^{3}$, Julie Poulain ${ }^{4}$, François Cousserans ${ }^{5}$, \\ Johann Schaller ${ }^{6}$, Marylène Poirié ${ }^{7}$, Beatrice Lanzrein ${ }^{2}$, Jean-Michel Drezen ${ }^{1}$, Sébastien JM Moreau ${ }^{1 *}$
}

\begin{abstract}
Background: Parasitic wasps constitute one of the largest group of venomous animals. Although some physiological effects of their venoms are well documented, relatively little is known at the molecular level on the protein composition of these secretions. To identify the majority of the venom proteins of the endoparasitoid wasp Chelonus inanitus (Hymenoptera: Braconidae), we have randomly sequenced 2111 expressed sequence tags (ESTs) from a cDNA library of venom gland. In parallel, proteins from pure venom were separated by gel electrophoresis and individually submitted to a nano-LC-MS/MS analysis allowing comparison of peptides and ESTs sequences.

Results: About $60 \%$ of sequenced ESTs encoded proteins whose presence in venom was attested by mass spectrometry. Most of the remaining ESTs corresponded to gene products likely involved in the transcriptional and translational machinery of venom gland cells. In addition, a small number of transcripts were found to encode proteins that share sequence similarity with well-known venom constituents of social hymenopteran species, such as hyaluronidase-like proteins and an Allergen-5 protein.

An overall number of 29 venom proteins could be identified through the combination of ESTs sequencing and proteomic analyses. The most highly redundant set of ESTs encoded a protein that shared sequence similarity with a venom protein of unknown function potentially specific of the Chelonus lineage. Venom components specific to C. inanitus included a C-type lectin domain containing protein, a chemosensory protein-like protein, a protein related to yellow-e3 and ten new proteins which shared no significant sequence similarity with known sequences. In addition, several venom proteins potentially able to interact with chitin were also identified including a chitinase, an imaginal disc growth factor-like protein and two putative mucin-like peritrophins.

Conclusions: The use of the combined approaches has allowed to discriminate between cellular and truly venom proteins. The venom of $C$. inanitus appears as a mixture of conserved venom components and of potentially lineagespecific proteins. These new molecular data enrich our knowledge on parasitoid venoms and more generally, might contribute to a better understanding of the evolution and functional diversity of venom proteins within Hymenoptera.
\end{abstract}

\section{Background}

Hymenopteran venoms have been intensively studied in social species such as bees, bumblebees, wasps, hornets and ants [1-6]. Most of the major allergens have been identified in species of medical importance through a combination of transcriptomic, proteomic, peptidomic

\footnotetext{
* Correspondence: sebastien.moreau@univ-tours.fr

'UMR 6035 CNRS, Institut de Recherche sur la Biologie de I'Insecte, Faculté des Sciences et Techniques, Université François-Rabelais, Parc Grandmont, 37200 Tours, France

Full list of author information is available at the end of the article
}

and glycomic techniques recently gathered under the newly proposed term of venomic approaches [7]. In comparison, little has been done on the venom composition of parasitoid Hymenoptera although they represent more than $75 \%$ of described hymenopteran species and $10-20 \%$ of all insect species [8]. Fundamental benefits expected from venomic approaches applied to parasitic wasp venoms would consist, for example, in the discrimination between cellular transcripts present in the venom glands and those encoding true venom proteins, through the proteomic analysis of venom fluid.

\section{() Biomed Central}


Moreover comprehensive analyses would allow a deeper characterization of weakly expressed venom components and a comparative work aiming at retracing the evolutionary history of hymenopteran venoms. Parasitoid venom proteins also constitute an underestimated source of toxins that could be studied for a variety of applied uses.

Parasitic wasps constitute by far the largest group of parasitic insects with an estimated total number of species of approximately 250000 [9]. Some develop outside (ectoparasitoids) and others inside (endoparasitoids) the body of an insect or other arthropod host and, depending on the species, various stages of the host can be parasitized (egg, egg-larval, larval, pupal and adult parasitoids). In ectoparasitoid species, venoms often induce paralysis and/or regulate host development, metabolism and immune responses [10-12]. Venom proteins from endoparasitic wasps are predominately involved in regulation of host physiology and immune responses alone or in combination with other factors of maternal origin such as polydnaviruses (PDVs) or virus-like particles present in the venom itself or produced in the ovaries and ovarian fluids [13-17]. For example, venoms can synergize the effects of PDVs $[18,19]$ and can interfere with host's humoral [20-22] and cellular immune components [23-26].

To date, less than 50 proteins have been individually identified and characterized from the venoms of a restricted number of parasitoid wasps species [15,27]. Broader studies have also previously investigated the composition of parasitoid venoms by the separate use of proteomic or transcriptomic approaches combined with bioinformatic analyses. A recent analysis of the venom proteome of the pupal ectoparasitoid wasp Nasonia vitripennis has been published, that benefited from the sequencing and annotation of this wasp genome [28]. Twelve venom proteins from the endoparasitoid Pteromalus puparum were also identified recently using a proteomic approach [29]. On the other hand, transcriptome analyses allowed the identification of venom proteins in the pupal endoparasitoid Pimpla hypochondriaca [30-32] and in two adult endoparasitoid species of the genus Microctonus [33]. Although these works are undoubtedly of great interest, most of them did not provide absolute evidence that all identified proteins were venom components. Therefore, there is still a crucial need for extensive analyses by combining various techniques of investigation at the molecular level to allow comparisons between species.

Chelonus inanitus (Hymenoptera: Braconidae) is original among the parasitoid species currently studied in being an egg-larval endoparasitoid species. Indeed it oviposits into the eggs of its host, Spodoptera littoralis (Lepidoptera: Noctuidae) and the parasitoid larva then develops inside the host embryo and early larval stages. Due to its lifestyle, $C$. inanitus must thus face up to particular physiological constraints imposed by its immature hosts. The venom, along with PDVs produced in the reproductive system of this wasp, are essential for successful parasitism as they protect the parasitoid from encapsulation by host's immune cells [34], interfere with the host's nutritional physiology [35] and induce a developmental arrest in the prepupal stage [18,36,37]. Venom of $C$. inanitus by itself alters the membrane permeability of host hemocytes, has a transient paralytic effect [38] and synergizes the effect of the PDVs on host development [18]. The data gathered on the functions of its venom make $C$. inanitus a valuable model for investigating the venom proteins. At least 25 proteins were found [38] but their sequences were unknown. The sequences of only two venom proteins from another species of the subfamily Cheloninae, Chelonus sp. near curvimaculatus, had been described to date $[39,40]$.

We report here the analysis of $C$. inanitus venom gland products based on the sequencing of clones of a cDNA library and on mass spectrometry analysis of venom proteins. This is the first time that this combination of techniques was applied to identify venom proteins from an endoparasitic wasp. The data obtained might contribute to acquiring a more comprehensive view on the origin and functional diversity of venom proteins among Hymenoptera.

\section{Results and Discussion}

\section{General overview of the cDNA library of $C$. inanitus venom gland}

The 2111 ESTs from the venom glands of $C$. inanitus were clustered into 488 clusters (95 contigs and 393 singletons, Table 1). The number of ESTs in each contig ranged from 2 to 534 and these clusters were considered as putative unigenes. The deduced sequences from 250 clusters (56 contigs and 194 singletons, $56.85 \%$ of all ESTs) shared significant similarities with protein sequences deposited in non-redundant databases (EMBL/Genbank), a proportion comparable to that found by Crawford et al. [33] which have studied the venom gland transcriptome of the parasitoid wasp Microctonus hyperodae. Of these products, 164 (corresponding to 36 contigs and 128 singletons, $21.5 \%$ of all ESTs) shared significant similarity with proteins with assigned molecular functions in the gene ontology database. This relatively low percentage is explained in part by the fact that the function of the most represented sequence (534 ESTs) referred below as Ci-23a, is unknown. At level 2 of the gene ontology system, clusters were classified into 9 molecular functional categories (Figure 1), among which "binding" (GO:0005488) 
Table 1 Summary statistics of the analysis of the C. inanitus venom gland ESTs

\begin{tabular}{|c|c|c|c|}
\hline & No. of clusters & No. of ESTs & Percentage of total ESTs \\
\hline Total no. of contigs (clusters with $>1$ member) & 95 & 1718 & 81.38 \\
\hline - coding for proteins identified by MS & 26 & 1272 & 60.26 \\
\hline - coding for other proteins & 69 & 446 & 21.13 \\
\hline Total no. of singletons (clusters with 1 member) & 393 & 393 & 18.62 \\
\hline - coding for proteins identified by MS & 7 & 7 & 0.33 \\
\hline - coding for other proteins & 386 & 386 & 18.29 \\
\hline TOTAL & 488 & 2111 & 100 \\
\hline
\end{tabular}

and "catalytic activity" (GO:0003824) categories were over-represented (95 and 82 clusters respectively). Interestingly, these categories were also the most common functional categories assigned to the venom glands ESTs from the saw-scaled viper, Echis ocellatus [41] and from the solitary hunting wasp species, Orancistrocerus drewseni [42]. Catalytic activity and binding categories thus constitute a hallmark of the venom gland transcriptomes analysed to date. A "structural molecule activity" function (GO:0005198) has been assigned to 48 clusters (20 contigs, 28 singletons) that corresponded essentially to genes coding for structural constituents of ribosomes (17 contigs, 21 singletons). In addition, products of genes functionally annotated as "translation regulator activity" (GO:0045182) (8 singletons) and "transcription regulator activity" (GO:0030528) (2 contigs, 15 singletons) were also identified, which encompassed transcriptional regulators, DNA or RNA binding proteins and translation elongation factors. All these proteins presumably reflect the metabolic effort invested by the venom gland for the transcription and translation of secreted products. The 2111 ESTs were used to produce in silico a database of venom gland open reading frames (vgORFs) which were matched to the peptide sequences obtained by nano-LC-MS/MS analysis. An overall of 1279 ESTs (26 contigs and 7 singletons, $60.6 \%$ of all ESTs) were then identified as coding for venom proteins of C. inanitus.

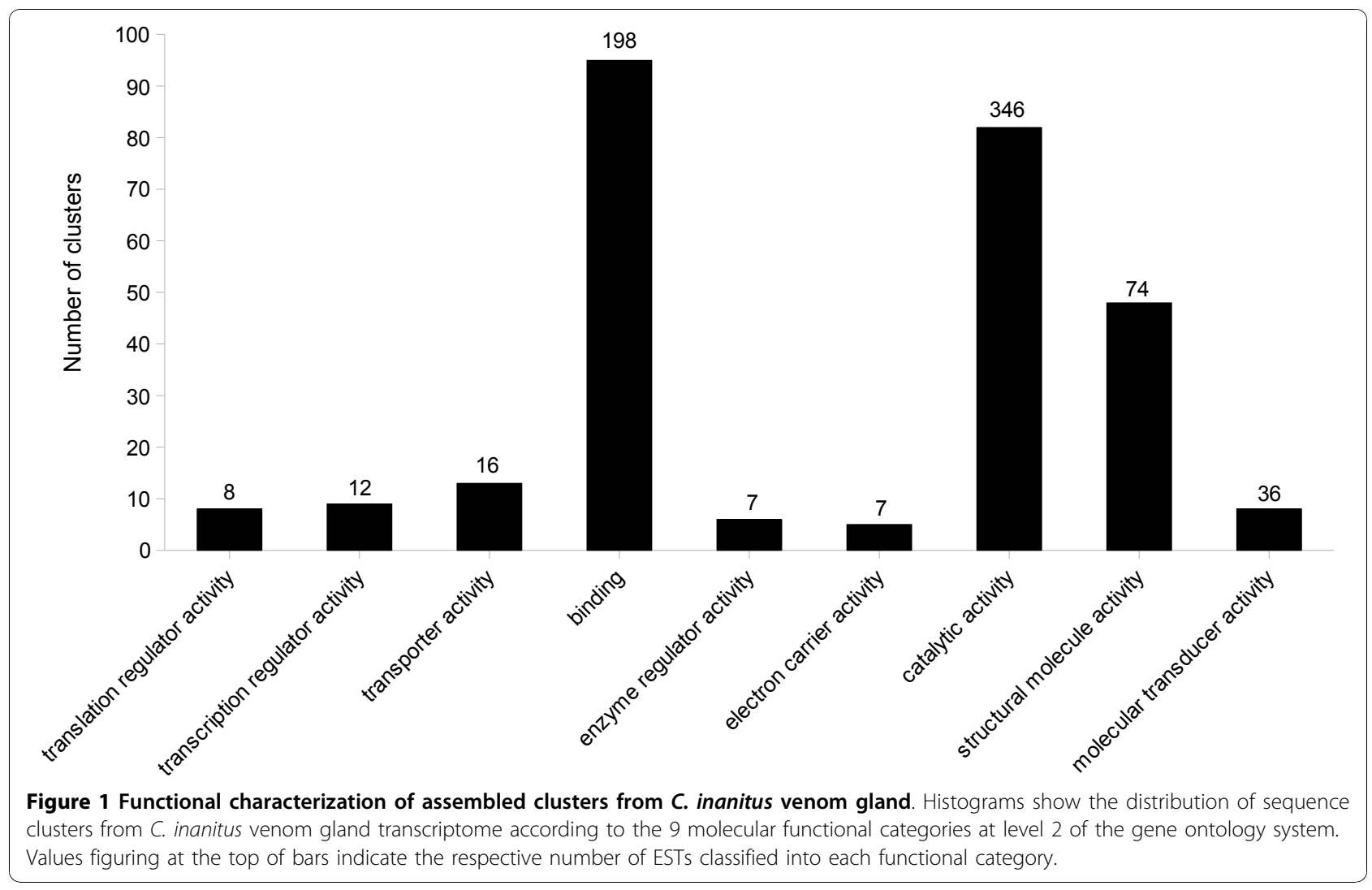


Identification of the venom proteins of $C$. inanitus

Venoms of parasitic wasps are reputed to have a low content in small proteins and peptides in comparison to venoms of social Hymenoptera [27,43]. Upon separation of C. inanitus venom proteins by SDS-PAGE, at least 25 proteins with apparent molecular masses ranging from 14 to $300 \mathrm{kDa}$ had been observed while no bands were seen below $14 \mathrm{kDa}$. This was also consistent with data previously reported [38] from the analysis of SDS-PAGE and two-dimension electrophoresis gels stained with Silver or Coomassie blue staining methods. For the nanoLC-MS/MS analysis presented here, several gradient gels (4-15\%) were run at various conditions to allow excision of all gel bands detectable upon Coomassie blue staining. Figure 2 shows that the analysed bands represent the majority of the venom proteins of $C$. inanitus. However, the presence in this venom of small amounts of additional proteins and peptides cannot be excluded. For 25 proteins, named $\mathrm{Ci}-14 \mathrm{a}$ to $\mathrm{Ci}-300$, peptide sequences exactly matching sequences of the vgORF database were obtained upon nano-LC-MS/MS analysis (see additional file 1: Table of peptide identification). Furthermore, peptides belonging to four additional proteins were detected, namely Vem7, Vem11, Vem17 and Vem37 (Vem being an abbreviation for Venom Mix). These proteins were found in several gel bands, a situation usually found for very abundant proteins. There was no evident correspondence between the relative abundance of venom protein bands on the gel (Figure 2) and the abundance of the corresponding ESTs in the vgORFs database (Table 2). The detailed list of the identified venom proteins will be discussed in the following sections.

\section{$\mathrm{Ci}-23 \mathrm{a}$ and $\mathrm{Ci}-45$, two proteins with similarities with venom proteins from $C$. sp. near curvimaculatus}

The Ci-23a venom protein was encoded by a contig corresponding to the highest number of ESTs in the library (534). It displays $50 \%$ of sequence identity (BlastP, Evalue $=7 \mathrm{e}-21)$ with a $32.5 \mathrm{kDa}$ protein referred as "venom protein from C. sp. near curvimaculatus" [GenBank:ACI70208.1], another chelonine wasp. This latter protein was historically the first to be isolated and sequenced from the venom of a parasitoid Hymenoptera [39]. Although it was found to be necessary for the survival of the parasitoid in the lepidopteran host, Trichoplusia $n i$ [44], it is still not related to any other known protein and its function remains unknown to date. A potential cleavage site for both $\mathrm{N}$-arginine dibasic convertase (pattern: .RK|RR[^ $\mathrm{KR}]$ ) and subtilisin-like proprotein convertase (pattern: [KR]R.) was detected at positions 51 to 53 (RRA) of the Ci-23a sequence. However, sequences coding for such convertases were not found in our vgORFs database. Remarkably, Ci-23a was

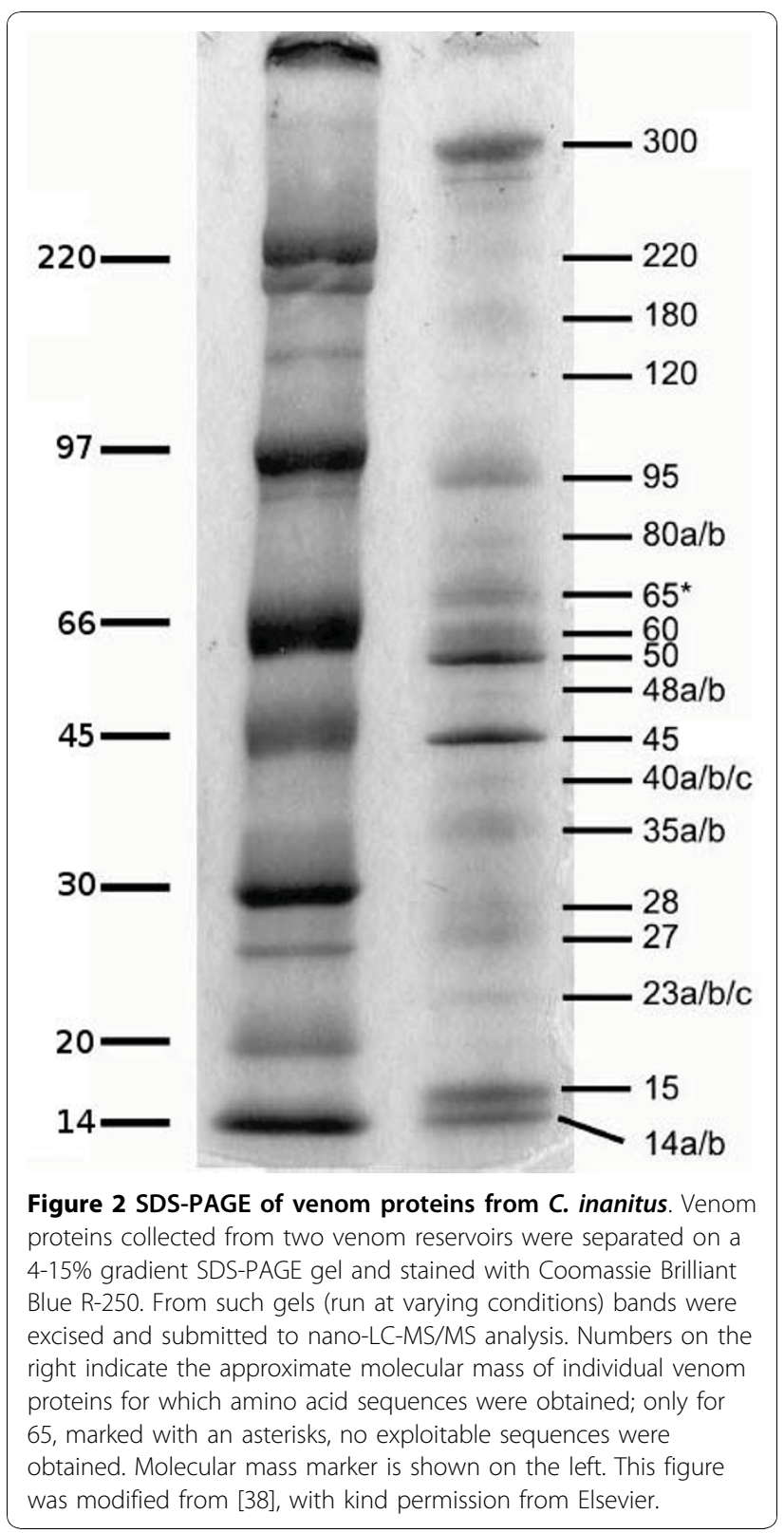

devoid of the 12 tandem repeats of 14 residues that characterized the C-terminal part of the venom protein of C. sp. near curvimaculatus (see additional file 2: Amino acid sequence alignment of $\mathrm{Ci}-23 \mathrm{a}$ and the venom protein from C. sp near curvimaculatus) [39]. These repeat sequences form several $\alpha$-helices with strong amphipathic structures supposed to run at the surface of the protein [39] and we found that they contain an unusualy high number of potential glycosaminoglycan attachment sites (14 serine motifs involved in the motif pattern: $[\mathrm{ED}]\{0,3\}$.(S) $[\mathrm{GA}])$. Thus $\mathrm{Ci}-23 \mathrm{a}$, which is much shorter than its homologue, is potentially processed by non-venomous convertases and is likely to have a substrate or target site specificity different from 
Table 2 List of venom proteins of C. inanitus identified by nano-LC-MS/MS analysis.

\begin{tabular}{|c|c|c|c|c|c|}
\hline Name & Identification & $\begin{array}{l}\text { EMBL Acc. } \\
\text { No }\end{array}$ & $\begin{array}{c}\text { Significant matches with Pfam } \\
\text { entries }\end{array}$ & $\begin{array}{l}\text { No. of corresponding } \\
\text { ESTs }\end{array}$ & $\begin{array}{c}\text { Seq. length } \\
\text { (amino acids) }\end{array}$ \\
\hline$\overline{C i-23 a}$ & $\begin{array}{l}\text { Similar to venom protein from C. sp. near } \\
\text { curvimaculatus }\end{array}$ & FN908672 & - & 534 & 114 \\
\hline $\mathrm{Ci}-45$ & Chitinase & FN908682 & PF00704 & 64 & 387 \\
\hline $\mathrm{Ci}-48 \mathrm{~b}$ & IDGF-like protein & FN908684 & PF00704 & 118 & 440 \\
\hline $\mathrm{Ci}-23 \mathrm{C}$ & Mucin-like peritrophin & FN908674 & PF01607 (×2) & 22 & 177 \\
\hline $\mathrm{Ci}-220$ & Mucin-like peritrophin & FN908692 & PF01607 (x2) & 3 & 229 \\
\hline Vem7 & Yellow-e3-like protein & FN908694 & PF03022 & 15 & 432 \\
\hline $\mathrm{Ci}-50$ & Esterase/lipase-like & FN908685 & PF00151 & 2 & $215^{p}$ \\
\hline $\mathrm{Ci}-300$ & Metalloprotease-like & FN908693 & - & 8 & $230^{p}$ \\
\hline Ci-95 & ACE-like protein & FN908689 & PF01401 & 19 & $145^{p}$ \\
\hline $\mathrm{Ci-80a}$ & C1A protease & FN908687 & PF00112 & 1 & $165^{p}$ \\
\hline $\mathrm{Ci}-40 \mathrm{a}$ & Trypsin-like serine protease & FN908678 & PF00089 & 2 & $144^{p}$ \\
\hline$\overline{C i-180}$ & Lectin-like protein & FN908691 & PF00059 & 2 & $218^{p}$ \\
\hline $\mathrm{Ci}-14 \mathrm{a}$ & CSP-like protein & FN908669 & PF03392 & 1 & $104^{p}$ \\
\hline $\mathrm{Ci-23b}$ & Protein related to PBP/OBP & FN908673 & PF01395 & 29 & 144 \\
\hline $\mathrm{Ci}-48 \mathrm{a}$ & Similar to lethal (1) G0193 isoforms & FN908683 & - & 5 & 383 \\
\hline Vem17 & Similar to lethal (1) G0193 isoforms & FN908696 & - & 3 & $220^{p}$ \\
\hline $\mathrm{Ci}-80 \mathrm{~b}$ & Similar to lethal (1) G0193 isoforms & FN908688 & - & 1 & $229^{p}$ \\
\hline $\mathrm{Ci}-14 \mathrm{~b}$ & Unknown protein & FN908670 & - & 286 & 141 \\
\hline $\mathrm{Ci}-15$ & Unknown protein & FN908671 & - & 4 & 123 \\
\hline $\mathrm{Ci}-27$ & Unknown protein & FN908675 & - & 59 & 210 \\
\hline $\mathrm{Ci}-28$ & Unknown protein & FN908676 & - & 13 & 182 \\
\hline $\mathrm{Ci}-35 \mathrm{a}$ & Unknown protein & FN908677 & - & 5 & $188^{p}$ \\
\hline $\mathrm{Ci}-35 \mathrm{~b}$ & Unknown protein & FN908678 & - & 5 & 266 \\
\hline$\overline{C i-40 c}$ & Unknown protein & FN908681 & - & 64 & $263^{p}$ \\
\hline $\mathrm{Ci}-60$ & Unknown protein & FN908686 & - & 2 & $205^{p}$ \\
\hline Vem11 & Unknown protein & FN908695 & - & 3 & 217 \\
\hline Vem37 & Unknown protein & FN908697 & - & 4 & 246 \\
\hline $\mathrm{Ci}-40 \mathrm{~b}$ & Acidic ribosomal protein P0 & FN908680 & PF00466 PF00428 & 3 & $316^{p}$ \\
\hline $\mathrm{Ci}-120$ & alpha-N-acetyl glucosaminidase & FN908690 & PF05089 & 2 & $165^{p}$ \\
\hline
\end{tabular}

Protein names for which a signal peptide has been predicted are shown in bold; $p$, partial sequence.

that of the $32.5 \mathrm{kDa}$ venom protein of $C$. sp. near curvimaculatus. Interestingly, the latter is a very abundant venom protein [44] while $\mathrm{Ci}-23 \mathrm{a}$ protein is of low abundance (Figure 2).

The $\mathrm{Ci}-45$ venom protein, which gives a strong band upon Coomassie staining (Figure 2), shows high similarity (BlastP, $79 \%$ identity, E-value $=2 \mathrm{e}-141$ ) to a $52 \mathrm{kDa}$ chitinase from venom of $C$. sp. near curvimaculatus [GenBank:AAA61639.1] [40]. Both proteins possess a predicted signal peptide and a glycosyl hydrolase family 18 domain (Pfam: PF00704) with four highly conserved regions present in all known insect chitinases [45-47] (see additional file 3: Amino acid sequence alignment of representative chitinases from different insect species). Members of glycosyl hydrolases 18 family show an eight-stranded $\alpha / \beta$ barrel catalytic core structure [48].
The 17 residues featuring this functional domain were all found in the $\mathrm{Ci}-45$ sequence, notably those of the second conserved region implicated in catalysis, as shown by previous site-directed mutagenesis studies (consensus sequence: (F/L)DG(L/I)DLD(W/I)EYP)) $[47,49]$. Four cysteine residues involved in two disulfide bonds are conserved in the two Cheloninae enzymes and the secondary structures of both proteins were predicted to be highly similar in the placement of $\alpha$-helix, $\beta$-strand and coil structure (data not shown). Ci-45 differs from its homologue by the absence of a C-terminal chitin-binding Peritrophin-A domain (CBM_14, Pfam: PF01607), but this domain does not appear to be essential for the chitinolytic activity of chitinases in Arthropods [46,50-52]. The Ci-45 contig is thus most likely coding for an active venom chitinase and might be 
responsible for the chitinase activity previously detected in the venom of $C$. inanitus [38]. According to the classification proposed by Zhu et al. [47], it belongs to a group of conserved insect chitinases containing a single catalytic domain (group IV). Our phylogenetic analysis (Figure 3) grouped the chitinases from venom glands of $C$. inanitus and C. sp. near curvimaculatus in a monophyletic clade with that from teratocytes of $T$. nigriceps [GenBank:AAX69085.1]. Teratocytes are parasitoid wasp secretory cells that circulate into the parasitized host haemolymph, and represent a different way for the wasp to deliver virulence factors into the host. The teratocyte released chitinase from $T$. nigriceps is hypothesized to contribute to the avoidance of microbial contamination of the host's haemocoel or to facilitate the emergence of parasitoid larvae through the host's cuticle [53]. Other examples of chitinases produced by venom glands were previously reported from spiders $[54,55]$ and from the parasitoid wasps $M$. hyperodae [33] and $N$. vitripennis [28]. More recently, a chitinase produced by the posterior salivary glands of the cephalopod Octopus kaurna has also been described [56]. Venom and salivary glands chitinases described are thus restricted to invertebrate species. Interestingly, our phylogenetic analysis shows that venom chitinases belong to distinct clades comprising also non venomous enzymes. This suggests chitinases have been selected for production in invertebrate venom glands through multiple independent recruitment events.

\section{Ci-48b, an IDGF-like protein}

Like $\mathrm{Ci}-45$, Ci-48b possesses a glycosyl hydrolase family 18 domain (see additional file 4: Amino acid sequence alignment of Imaginal disc Growth Factors (IDGFs)-like proteins from different insect species). However, in the second conserved region, a glutamine residue (Q157) replaces the glutamic acid residue that plays a key role in active insect and bacterial chitinases, in being the putative proton donor during the catalytic mechanism $[49,57,58]$. This feature is shared by members of the imaginal disc growth factors (IDGFs) family which have presumably evolved from chitinases to gain new functions [59]. Interestingly, $\mathrm{Ci}-48 \mathrm{~b}$ shows high sequence similarity to IGDFs from several insect species, namely a venom gland protein of honey bee workers [NCBI Reference Sequence: XP_396769.2] and a hemocyte aggregation inhibitor protein from the lepidopteran species Manduca sexta [GenBank:ACW82749.1] (Blast P 38\% identity; E-value = 2e-76) [60]. Thus $\mathrm{Ci}-48 \mathrm{~b}$ may contribute to the survival and development of $C$. inanitus

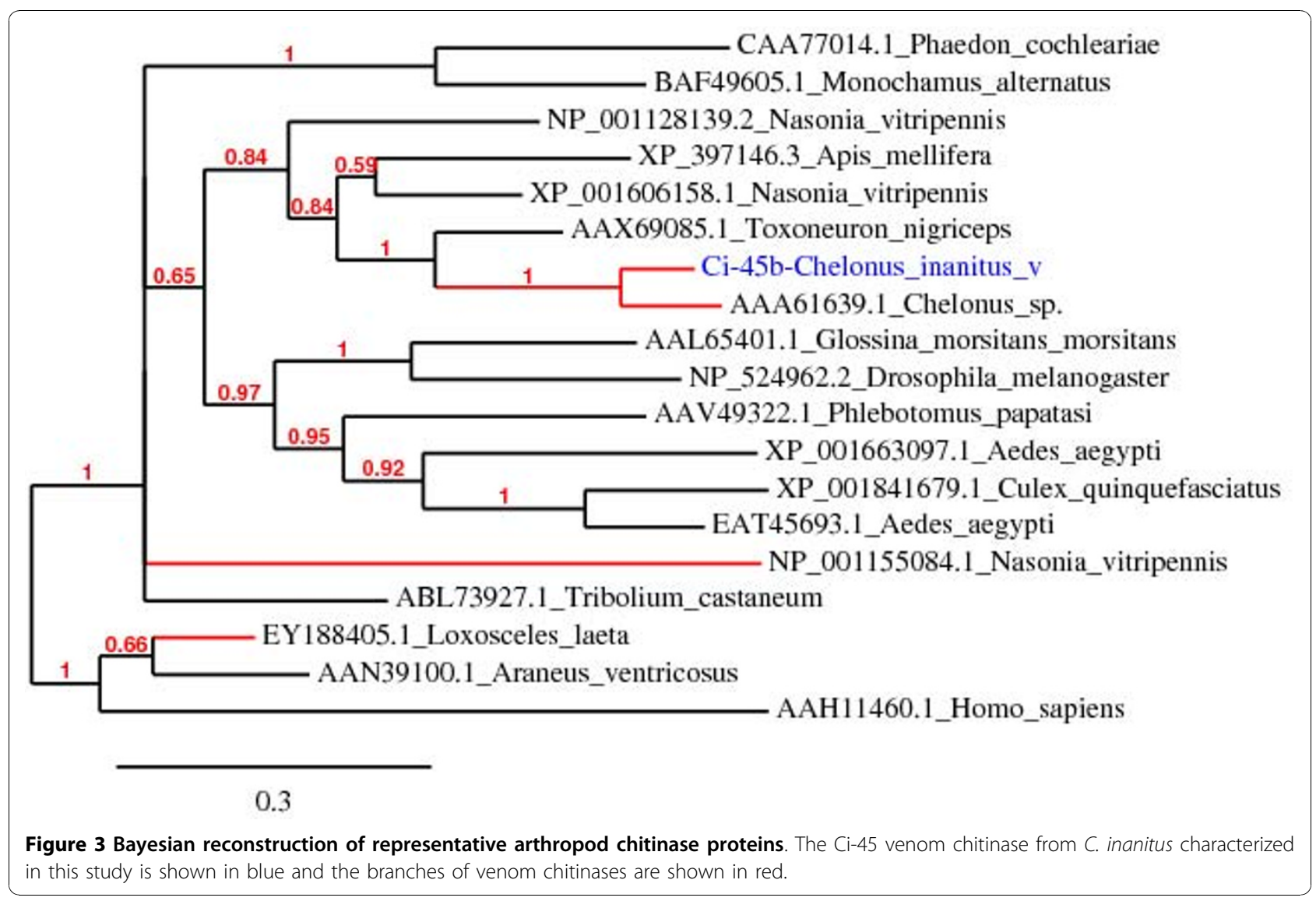


eggs once oviposited into their host either by acting as a growth factor or alternatively, by modulating the cellular immune response of young $S$. littoralis host larvae.

\section{$\mathrm{Ci}-23 \mathrm{C}$ and $\mathrm{Ci}-220$, two putative mucin-like peritrophins}

The sequence of the $\mathrm{Ci}-23 \mathrm{c}$ venom protein is 177 amino acid long, giving a theoretical molecular mass of 19.6 $\mathrm{kDa}$ (see additional file 5: Amino acid sequence alignment of $\mathrm{Ci}-23 \mathrm{c}, \mathrm{Ci}-220$ and $\mathrm{AD}-873)$. It possesses two Chitin-binding peritrophin domains 14 (CBM_14, positions 26-78 and 92-144) and a predicted glycosaminoglycan attachment site (positions 155-158). Another venom protein, $\mathrm{Ci}-220$ (229 amino acids, theoretical molecular mass $26.3 \mathrm{kDa}$ ), also contains two CBM_14 domains (positions 29-84 and 82-135) and a predicted glycosaminoglycan attachment site (positions 138-141). The two proteins share an overall $32 \%$ identity (BlastP, E-value $=1 \mathrm{e}-16)$ and show sequence similarities to a wide variety of CBM_14 domains containing proteins, including a venom component from $N$. vitripennis [28]. Moreover they share the domain organization of the mucine-like peritrophin AD-873 identified from the salivary gland transcriptome of the mosquito Anopheles darlingi [GenBank:ACI30179.1]. Interestingly this peritrophin is speculated to contribute to the maintenance of the structure of the mouthparts and/or salivary canal of $A$. darlingi [61]. In $C$. inanitus, oviposition is accompanied by intense contractions of the abdomen, which are necessary to push the venom from the reservoir into the oviduct, since the venom reservoir is located at the distal end of one of the gland filaments and has a very thin wall without a muscle layer [38]. It is thus possible that the venom proteins $\mathrm{Ci}-23 \mathrm{c}$ and $\mathrm{Ci}-220$, as the mosquito peritrophin, contribute to keeping the reservoir in shape.

\section{Vem7, an ancient yellow-e3-like venom protein}

Vem7 shares high sequence similarity to the yellow-e3 protein [GenBank:ABB82366.1] from A. mellifera (BlastP, 42\% identity, E-value $=2 \mathrm{e}-81$ ). The yellow-e 3 gene is highly expressed in the head and hypopharyngeal gland of honey bee workers and is considered as the progenitor of all genes of major royal jelly proteins (MRJPs) of $A$. mellifera. Located in the same genomic region and sharing a similar exon/intron organization, MRJPs would have been generated via recent duplications [62,63]. Recently, two members of the MRJPs family, MRJP8 [GenBank:ACD84799.1] and MRJP9 [GenBank:ACD84800.1], were identified in the venom gland proteome of $A$. mellifera [5]. It is noteworthy that phylogenetic analyses put them at the basis of the MRJPs tree, meaning that they are the most ancient members of the MRJPs family and suggesting a venomous "pre-royal jelly" function for the MRJPs progenitor originating from yellow-e3 [5,63]. Our phylogenetic analysis shows that Vem7 forms a monophyletic group with yellow-e-3 protein (Figure 4) and thus represents the first example of a venomous protein in this clade. This supports the hypothesis that a yellow-e-3 gene progenitor of MRJPs may have encoded a venomous protein like the Vem7 gene.

\section{Putative enzymes}

$\mathrm{Ci}-50$ is a venom protein belonging to the lipase family (Pfam: PF00151). One carboxyl-esterase and two other lipases were previously identified in the venom proteome of $N$. vitripennis [28] and a lipase activity has been found in the venom of $P$. hypochondriaca [64]. In $N$. vitripennis, venom lipases might participate in the alteration of host's lipid metabolism to the benefit of the developing parasitoid eggs [65] and a similar function is conceivable for $C$. inanitus.

The partial sequence of the $\mathrm{Ci}-300$ venom protein shares 39\% sequence similarity (BlastP, E-value $=2 \mathrm{e}-05$ ) with a Zinc-dependent metalloprotease identified in the venom of $P$. hypochondriaca [GenBank:CAD21587.1]. However, Ci-300 lacks the functional characteristic $\mathrm{Zn}^{2}$ ${ }^{+}$-binding motif of HExxHxxGxxH and a distal located methionine [66] found in venom metalloproteinases from the parasitoid species $P$. hypochondriaca [67], $M$. aethiopoides [33], Eulophus pennicornis [68] and $N$. vitripennis [28] (see additional file 6: Partial amino acid sequence alignment of $\mathrm{Ci}-300$ with insect metalloproteases). The sequence of $\mathrm{Ci}-300$ could have thus considerably diverged from an ancestral Zinc-dependent metalloprotease-like protein to acquire an original function in the venom of $C$. inanitus.

The Ci-95 venom protein shows significant sequence similarity to various angiotensin converting enzymes (ACEs, Pfam: PF01401) and notably to an ACE-like protein from A. mellifera [NCBI Reference Sequence: XP_393561.2] (BlastP, 46\% identity, E-value $=2 \mathrm{e}-29$ ). In addition, upon Western analysis with an antibody made against recombinant Drosophila ACE (kindly provided by Dr. Elwyn Isaac, University of Leeds, UK) a clear band was seen (data not shown). ACE is a dipeptidyl carboxydipeptidase with a broad in vitro substrate specificity that is best known, in mammals, for its role in converting inactive angiotensin I to the vasoconstrictor, angiotensin II, and the inactivation of bradykinin [69]. In insects, ACE-like proteins appear to have a wide tissue distribution, from embryos to adult stages $[70,71]$ and some have been implicated in the metabolic inactivation of neuropeptides in the central nervous system [72]. Dani et al. [73] have detected an ACE-like enzymatic activity in the venom of $P$. hypochondriaca and have speculated that venomous ACE could be involved in the processing of peptide precursors in the venom 


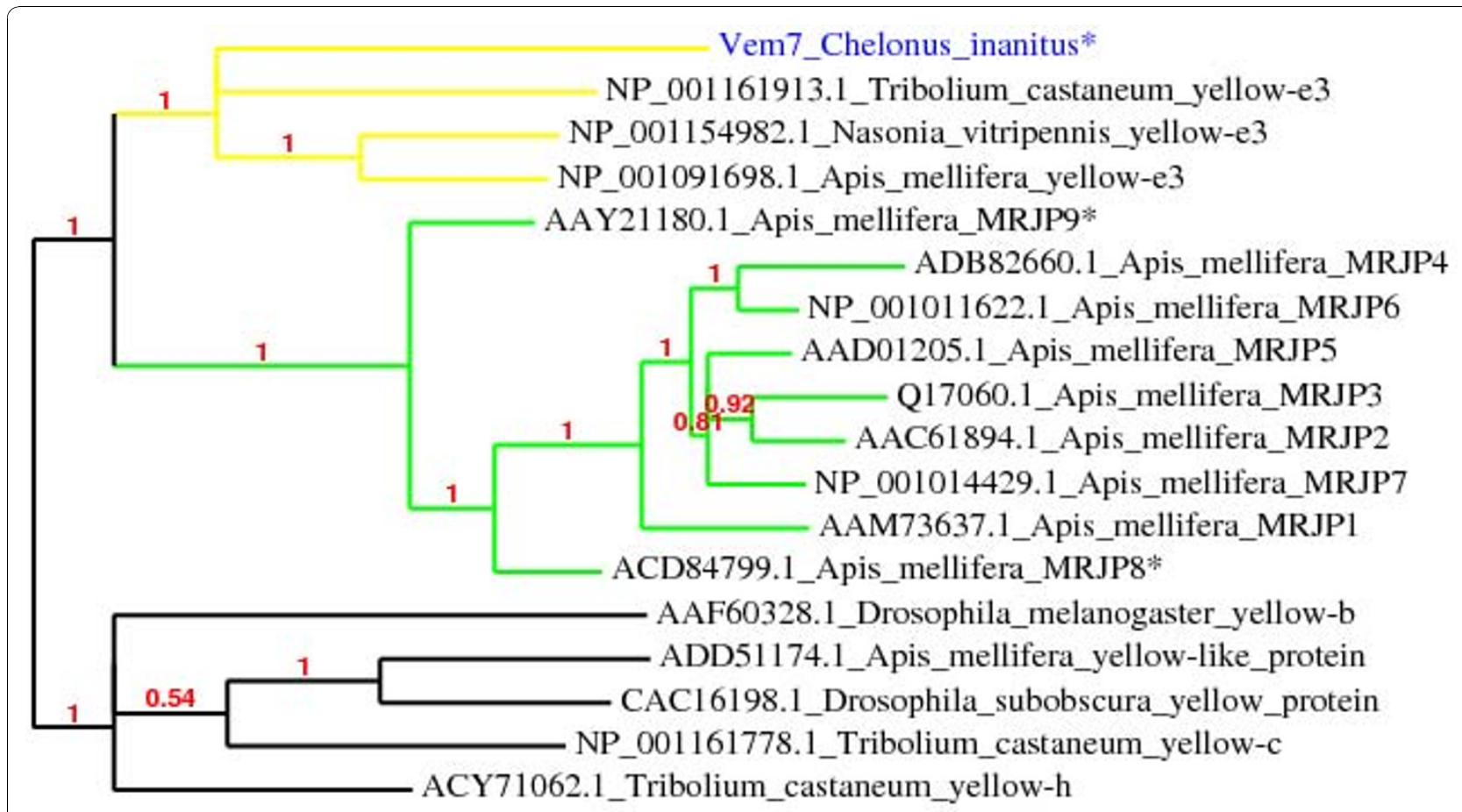

0.3

Figure 4 Bayesian reconstruction of representative yellow-e3 and MRJPs proteins. The Vem7 protein from C. inanitus characterized in this study is shown in blue. Yellow proteins clades are shown in yellow and MRJPs clades are shown in green. Asterisk indicates protein expressed by venom glands.

reservoir. More recently, another ACE-like enzyme has also been identified in the venom of $N$. vitripennis [28].

$\mathrm{Ci}-80 \mathrm{a}$, a venom protein encoded by a single transcript identified in our VgORFs database, belongs to the peptidase family $\mathrm{C} 1$, sub-family $\mathrm{C} 1 \mathrm{~A}$ (papain family, clan CA, Pfam: PF00112). The partial sequence of $\mathrm{Ci}-80 \mathrm{a}$ contains two out of the four conserved residues of the active site of C1A proteases and all the residues involved in the S2 subsite, which is involved in specificity for the dominant substrate of papain-like cysteine proteases. Interestingly, viral cystatins encoded by the genome of the bracovirus $\mathrm{CcBV}$, associated with the parasitic wasp Cotesia congregata, were shown to target some C1A proteases of the host $M$. sexta [74]. Cathepsins and their inhibitors may play an important role, yet undetermined, in the context of host-parasitoid physiological relationships.

The Ci-40a venom protein contains a partial trypsinlike serine protease domain (Pfam: PF00089) but displays low sequence similarities with other known proteases (see additional file 7: Amino acid sequence alignment of $\mathrm{Ci}-40 \mathrm{a}$ with serine protease homologs (SPHs)). At least one of the three residues involved in the catalytic triad for serine protease (aspartate residue in position 111 ) is present in the partial sequence of $\mathrm{Ci}-40 \mathrm{a}$. Several serine protease homologs were already reported from parasitoid venoms. In the endoparasitoid C. rubecula, the venom protein Vn50 [GenBank:AAP49428.1] has been found to be a mutated serine protease acting as an inhibitor of the defensive reaction of melanization of host hemolymph [21]. In addition, members of the serine protease protein family were recently identified in the venom proteomes of $N$. vitripennis [28] and $P$. puparum [29].

The $\mathrm{Ci}-120$ protein shares significant sequence similarity with insect alpha- $\mathrm{N}$-acetyl glucosaminidases (Pfam: PF05089, EC: 3.2 .1 .50 ) and might play a role in proteoglycan metabolism.

\section{Lectin-like venom protein}

A C-type lectin domain (Pfam: PF00059) was found in the sequence of the $\mathrm{Ci}-180$ venom protein. The domain extends from positions 76 to 199 of the partial sequence. An immunosuppressive function has been proposed for a lectin with a similar C-type lectin domain, encoded by the genome of the bracovirus $\mathrm{CpBV}$, associated with the parasitic wasp Cotesia plutellae [75]. Since parasitoid venoms and PDVs are used by the wasps to manipulate parasitized host physiology, it 
might not be surprising that common molecules have been selected for delivery into the host via different pathways.

\section{CSP-like and OBP-like proteins}

The $\mathrm{Ci}-14 \mathrm{a}$ venom protein belongs to the A10/OS-D insect pheromone-binding protein family (Pfam: PF03392). A high sequence similarity was observed between $\mathrm{Ci}-14 \mathrm{a}$ and Csp3 from A. mellifera (BlastP, 56\% identity, E-value $=5 \mathrm{e}-27$ ), another member of the A10/ OS-D protein family. Csp3 [GenBank:ABH88171.1] is a chemosensory protein (CSP) ubiquitously expressed in adults and pre-imaginal stages of the honeybee in which it may play a role in cuticle maturation [76].

$\mathrm{Ci}-23 \mathrm{~b}$ is a venom protein containing a pheromone binding protein/general-odorant binding protein (PBP/ GOBP) domain (Pfam: PF01395). Homology searches revealed that $\mathrm{Ci}-23 \mathrm{~b}$ has highly diverged from known PBPs and GOBPs. In particular, it only shows 4 out of the 6 cystein residues strictly conserved between PBPs and GOBPs $[77,78]$. Other OBP-like venom proteins, unrelated to $\mathrm{Ci}-23 \mathrm{~b}$, have previously been identified in the venom proteomes of $A$. mellifera workers and $N$. vitripennis females (NCBI Reference Sequences: NP_001035313.1 and NP_001155150.1, respectively) $[5,28]$. Beside the involvement of PBPs and OBPs in chemical communication, it is possible that in Hymenoptera, some OBP-like proteins fulfil other roles in relation with the venomous functions.

\section{Venom proteins similar to lethal (1) G0193 isoforms} $\mathrm{Ci}-48 \mathrm{a}, \mathrm{Vem} 17$ and $\mathrm{Ci}-80 \mathrm{~b}$ venom proteins share sequence similarities with members of a group of proteins similar to protein isoforms A [GenBank: AAF46301.1] and B [GenBank:AAS65275.1] encoded by the lethal (1) G0193 gene from D. melanogaster. This group of cystein-rich proteins notably includes several venom and salivary gland proteins of unknown functions reported from various insect species (see additional file 8: Sequence similarities between $\mathrm{Ci}-48 \mathrm{a}, \mathrm{Vem} 17$ and $\mathrm{Ci}-80 \mathrm{~b}$ and proteins similar to isoforms of lethal (1) G0193). Ci-80b possesses the least conserved amino acid sequence towards lethal (1) G0193 isoforms suggesting it might have diverged as a virulence factor involved in host-parasite interactions, which are often characterized by a high level of divergence.

\section{New lineage-specific proteins}

In addition to $\mathrm{Ci}-23 \mathrm{a}$ and $\mathrm{Ci}-45$ which are conserved in the venom of two Chelonus species, ten $C$. inanitus venom proteins did not show any significant sequence similarity to known proteins $(\mathrm{Ci}-14 \mathrm{~b}, \mathrm{Ci}-15, \mathrm{Ci}-27, \mathrm{Ci}-$ 28, Ci-35a, Ci-35b, Ci-40c, Ci-60, Vem11 and Vem 37). This is reminiscent of observations on twenty three venom proteins in $N$. vitripennis which also have no similarity to known proteins and appear to be lineageand/or species specific [28]. Given that Chelonines are egg-larval parasitoids it is possible that new C. inanitus proteins have evolved to cope with this particular parasitic context. Although they do not contain conserved domains, they may play an important role during hostparasite interaction and notably $\mathrm{Ci}-14 \mathrm{~b}$, the second most abundant sequence of the transcriptome (286 ESTs).

\section{Additional putative venom proteins identified from the vgORFs database}

In addition to proteins identified by mass spectrometry, several ESTs encoding putative venom proteins were identified in our vgORFs database (Table 3). Five ESTs encoded partial sequences of at least three different hyaluronidase-like proteins that show significant sequence similarities to venom hyaluronidases described from several hymenopteran species [79]. One EST encoded a

Table 3 Additional putative venom proteins identified by similarity searches (BLASTP).

\begin{tabular}{|c|c|c|c|c|c|}
\hline $\begin{array}{l}\text { Sequence } \\
\text { name }\end{array}$ & EMBL Acc. no. & Best-matched Protein (Acc. no.) & Species & Id. (\%) & E-value \\
\hline A6YN21CM1 & FN985040 & $\begin{array}{c}\text { Hyaluronidase } \\
\text { [GenBank:ACD61711.1] }\end{array}$ & Orancistrocerus drewseni & 37 & $2 e-16$ \\
\hline A4YE08CM1 & FN985041 & $\begin{array}{c}\text { Hyaluronidase } \\
\text { [GenBank:AAA27730.1] }\end{array}$ & Apis mellifera & 46 & $7 e-07$ \\
\hline A3YM10CM1 & FN985042 & $\begin{array}{c}\text { Hyaluronidase } 2 \\
\text { [GenBank:AAK51798.2] }\end{array}$ & Apis cerana cerana & 45 & $8 e-36$ \\
\hline A2YM17CM2 & FN985043 & $\begin{array}{c}\text { Hyaluronidase } \\
\text { [GenBank:BAF93867.1] }\end{array}$ & Anoplius samariensis & 37 & $6 e-13$ \\
\hline A1YB14CM3 & FN985044 & $\begin{array}{c}\text { Hyaluronidase } \\
\text { [GenBank:AAA27730.1] }\end{array}$ & Apis mellifera & 42 & $7 e-43$ \\
\hline $\mathrm{A} 1 \mathrm{YI} 24 \mathrm{CM} 3$ & FN985045 & $\begin{array}{c}\text { Allergen 5 } \\
\text { [GenBank:AAA28303.1] }\end{array}$ & Dolichovespula arenaria & 48 & $7 e-36$ \\
\hline
\end{tabular}

Amino acid sequences encoded by the mentioned ESTs were compared to protein sequences deposited in NCBI nr database using BLASTP algorithm. Id.: identity between the amino acid sequence deduced from a given $C$. inanitus transcript and the corresponding best-matched protein. 
venom allergen 5-like protein (Figure 5). Venom allergen 5 proteins (also called antigens 5 ) are commonly found in venoms of social Hymenoptera of the superfamilly Vespoidea [80]. They belong to a wider group of proteins expressed by salivary and venom glands of distant animal species, recently gathered under the proposed term of CAP proteins for "Cystein-rich secretory proteins, Antigen 5 and Pathogenesis-related proteins" [56]. CAP domain proteins are the dominant allergyinducing toxins in hymenopteran venoms [81], and a related CAP protein has previously been identified from the venom of M. hyperodae [33].

\section{Conclusions}

In this paper we report the identification of the majority of venom proteins of the egg-larval endoparasitoid wasp C. inanitus. We combined technical approaches which we had successfully used to elucidate the origin of bracoviruses [82]. They are powerful tools to study evolutionary and functional aspects of parasitoid-associated factors. The most highly redundant set of sequences encoded a protein (Ci-23a) that shared sequence similarity with a venom protein previously identified in the related species $C$. sp. near curvimaculatus [39]. These venom proteins are thus likely to play a key role, as yet undetermined, in the life cycle of Cheloninae egg-larval endoparasitoids. In addition, we have identified 453 unigenes that, for the most part, are likely to code for nonsecretory products of the venom glands.

A striking feature of $C$. inanitus venom was the redundancy of components able to interact with chitin. These components might be important when intermediate or late stages of eggs are parasitized. In this case, the parasitoid larva has to bore itself into the host embryo which is surrounded by an embryonic cuticle [83] and chitinases might help to facilitate this process.

A number of $C$. inanitus venom proteins and enzymes shared similarities to venom gland products from other species that also belong to the Ichneumonoidea superfamily (M. hyperodae, M. aethiopoides, P. hypochondriaca). Sequence similarities were also found with venom proteins from more distant apocritan species representative from Chalcidoidea (N. vitripennis), Vespoidea (O. drewseni, Anoplius samariensis, Dolichovespula arenaria) and Apoidea (A. mellifera, Apis cerana cerana) superfamilies (see additional file 9: Phylogeny of the major superfamilies of Hymenoptera). The presence of related venom proteins in species that do not share the same ecological constraints and lifestyles can partly be explained by independent recruitment of these

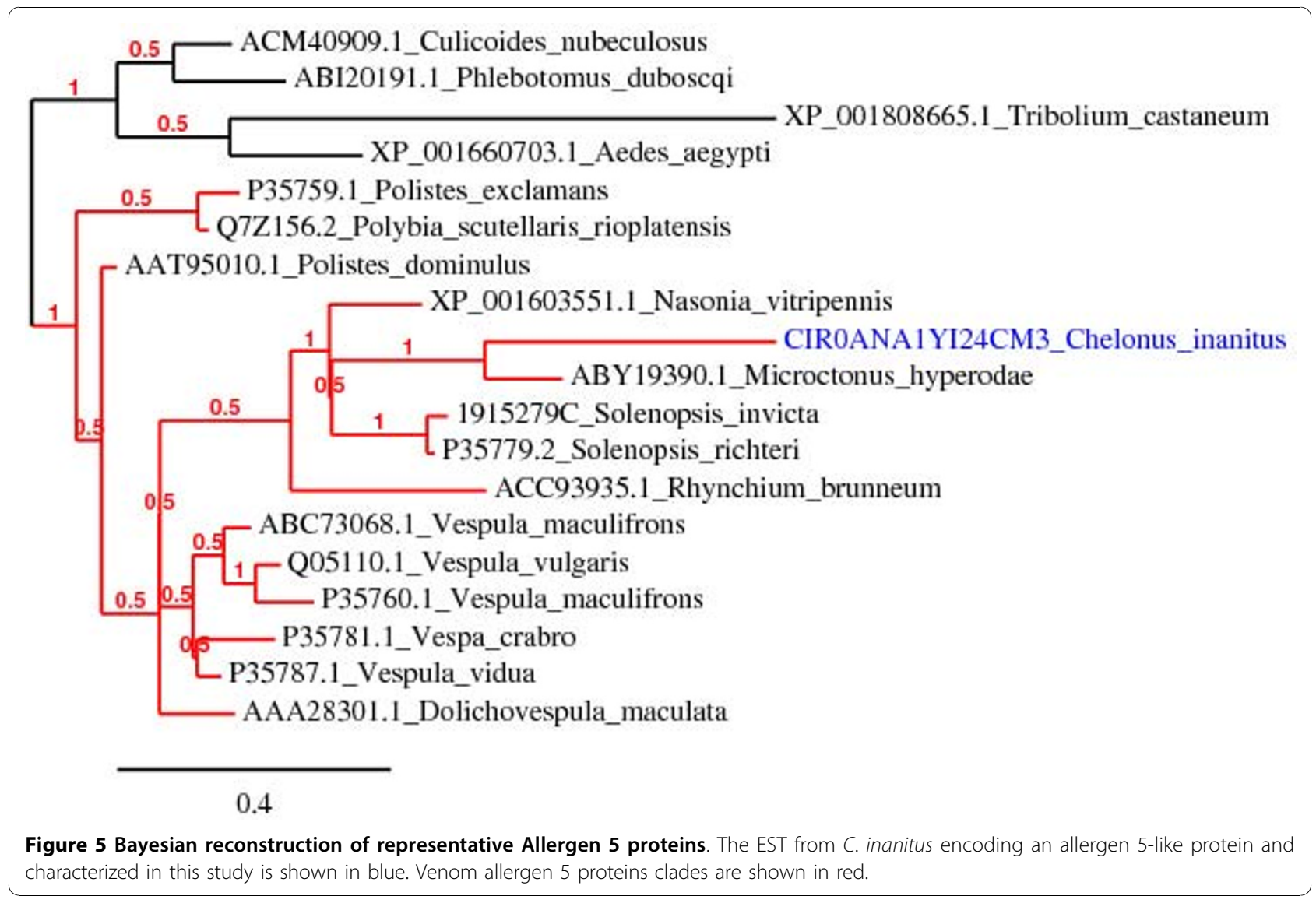


proteins during species evolution [56]. Our phylogenetic analyses suggest this is the case for the venom chitinases of the Cheloninae species and the venom chitinase 5 of $N$. vitripennis that were acquired independently. However, given that all modern Apocrita share a common ancestral parasitic origin [84], it is also expected that some lineages have conserved ancestral venom genes. Our finding of mRNA coding for a member of the allergen 5 proteins family in the venom glands of $C$. inanitus appears to be an example of such conservation. The sequence of the deduced protein is placed, with the allergen 5 from the venom of $M$. hyperodae and $N$. vitripennis in a monophyletic clade with respect to the phylogenetic tree of allergen 5 proteins found in vespid and ant venoms (Figure 5). This result suggests that the ancestral gene was expressed by the venom glands of the common ancestor of Ichneumonoidea and Aculeata, 155 to 185 million years ago [84] and could have been lost in Apoidea. Allergen 5 proteins would thus be representative of one of the most ancient group of insect venom proteins.

Another interesting point is the discovery of a yellowe3-like protein, Vem7, in the venom of C. inanitus which give more indications on the evolutionary history of the yellow-e3 gene family among Hymenoptera. Interestingly the recent genome sequencing of $N$. vitripennis has revealed the largest number of yellow/MRJP genes so far found in any insect, including an independent amplification of MRJP-like proteins [85]. It would be worthy to determine if some of these genes have a venomous function in Nasonia species.

On a more general standpoint, once increasing number of comprehensive analyses will become available, our work on the venom composition of $C$. inanitus will contribute to retracing the evolution of venomous functions within Hymenoptera by comparison of the venomous arsenal of different species.

\section{Methods}

\section{Insects}

C. inanitus (Hymenoptera: Braconidae), a solitary egglarval parasitoid, was reared on one of its natural hosts S. littoralis. Adult S. littoralis were kindly provided by Syngenta AG, Stein, Switzerland. They were raised at $27^{\circ} \mathrm{C}$ at a LD photoperiod of $14 \mathrm{~h}: 10 \mathrm{~h}$ and fed with an artificial diet. Diet was prepared from dry powder (Beet Army Worm Diet, Bio Serv, Frenchtown, New Jersey, USA).

\section{Collection of venom glands and RNA isolation}

Female wasps were anaesthetized on ice for several minutes and then shortly rinsed in $70 \%$ ethanol. The abdominal organs were gently pulled out with forceps and the reproductive apparatus was placed in $50 \mu \mathrm{l}$ sterile Insect Ringer. Then, the venom gland filaments were dissected, washed in sterile Ringer, put into an Eppendorf tube containing $200 \mu \mathrm{l}$ of RNAlater ${ }^{\mathrm{Tm}}$ (Qiagen) and stored at $-80^{\circ} \mathrm{C}$ until RNA isolation. The morphology of the C. inanitus venom gland was previously described by Kaeslin et al. [38]. For RNA isolation, venom gland filaments from 60 female wasps were used; no homogenization was necessary and $0.45 \mathrm{ml}$ Lysis buffer RLT (Qiagen) including $143 \mathrm{mM} \beta$-mercaptoethanol was added followed by a proteinase $\mathrm{K}$ digestion as described by Johner and Lanzrein [86]. The RNA isolation (RNeasy Mini Kit, Qiagen) including an on column DNase digestion (RNase-free DNase I) was performed according to the manufacturer's protocol. Total RNA was eluted from the column with $100 \mu \mathrm{l}$ RNase-free water. A second digestion with DNase I was carried out and the RNA was then extracted with acidic phenol; the RNA was precipitated as described in [87]. The yield was $9 \mu \mathrm{g}$ of total RNA.

\section{cDNA library construction}

A cDNA library was constructed with the Creator SMART cDNA Library Construction Kit (BD Biosciences, Ozyme, France) following the supplier's instructions. The first strand cDNA was synthesized from 481 ng of total RNA extracted from C. inanitus venom glands. The cDNA were ligated into pDNR-LIB (BD Biosciences Clontech) and ligation products were transformed into ElectroMax DH10B-T1 Phage Resistant Escherichia coli Competent Cells (Invitrogen, Fisher Scientific, France).

\section{Sequencing and ESTs quality control}

To obtain an unbiased overview of the venom gland transcriptome, colonies were amplified with the $\varphi 29$ DNA polymerase by rolling circle amplification. Sequencing was done on a ABI sequencer using the standard M13 forward primer and BigDye terminator cycle sequencing kit (Applied Biosystems, Foster City, CA, USA). Initially 384 clones from the library were analyzed for the presence of venom proteins-related sequences. These were detected and a sequencing of a total of 2500 clones was performed. The EST sequences obtained were analysed for quality control; base calling step was performed with the Phred program $\mathrm{f}(\mathrm{S} 9)$. Low quality bases (phred score $<20$ ) were masked and sequences with more than $30 \% \mathrm{n}$-content, or shorter than $60 \mathrm{bp}$ (after vector/adaptator sequences removing) were removed.

\section{ESTs clustering and assembly}

After discarding the poor-quality sequences, 2111 highquality ESTs were subjected to clustering using the TIGR software TGI Clustering tool (TGICL) [88]. The 
clustering was performed by a modified version of NCBI's megablast. EST sequences were assigned to clusters based on identity: the clustering parameters were 98\% minimum percent identity for overlaps, for a minimum overlap length of $40 \mathrm{nt}$ and a maximum length of unmatched overhangs of $20 \mathrm{nt}$.

Sequences from each cluster were assembled into consensus sequences called "contigs" using the CAP3 assembly program [89] available in TGICL. Sequences from a cluster containing only one sequence were called "singletons".

\section{ESTs annotation}

To identify similarities with known proteins, the sequences of contigs and singletons were searched using the BLASTX algorithm against a local non-redundant protein database (NR, NCBI) with a cut-off E-value of $1 \mathrm{e}-5$. To define the function of the contigs and singletons, we used the Gene Ontology (GO) controlled vocabulary [90] and more particularly GOSlim, a subset of GO terms, which provides a higher level of annotations and allows a more global view of the dataset. To this end, an automated GO-annotation of the sequences of contigs and singletons that showed a significant similarity with a Uniprot entry was achieved using the Blast2go software [91], with a stringency cut-off of 1e-6.

\section{Collection of venom, SDS-polyacrylamide gel electrophoresis and protein identification}

Wasps were anaesthetized on ice and their venom apparatus (venom gland filaments and reservoir) was dissected. For each protein separation the venom of four wasps was collected. The venom was collected by piercing the reservoirs with a glass capillary. The sucked up venom was collected in $10 \mu \mathrm{l}$ sterile $\mathrm{H}_{2} \mathrm{O}$ and mixed with $10 \mu$ sample buffer $(0.125 \mathrm{M}$ Tris- $\mathrm{HCl} \mathrm{pH} 6.5,4 \%$ (w/v) SDS, $10 \%$ (v/v) glycerol, $0.01 \%$ bromophenol blue, $5 \%(\mathrm{v} / \mathrm{v}) \beta$-mercaptoethanol) and heated at $90^{\circ} \mathrm{C}$ for 6 minutes. For separation of proteins, precast linear gradient READY GEL (BIO RAD) 4-15\% Tris- $\mathrm{HCl}$ gels with 10 wells were used. Two equivalents of venom (i.e. the amount of venom collected from two reservoirs) were loaded per lane. Electrophoresis was in $0.02 \mathrm{M}$ Tris- $\mathrm{HCl}$ $\mathrm{pH}$ 8.8, $0.19 \mathrm{M}$ glycine, and 0.1\% (w/v) SDS. A constant voltage of $150 \mathrm{~V}$ was applied. As marker the High-

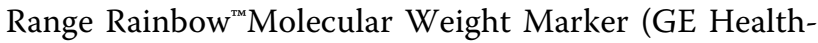
care) was used. Staining was done with SERVA blue $\mathrm{R}$ (Coomassie) Brilliant Blue R-250 according to the manufacturer's protocol. For protein identification, gel slices were cut out, transferred into Eppendorf tubes and covered with $20 \mu \mathrm{l}$ ethanol (20\%). Treatment of gel slices and nano-LC-MS/MS analysis was as described in [82]. CID spectra were extracted into data files by Bioworks (Rev.3.3.1, Thermo Scientific) without any filters applied.
Combined dta files were automatically matched to our personal database of vgORFs by Phenyx software, Version 2.5 (Genebio SA, Geneva, Switzerland). N-terminal sequencing was done by Edman degradation.

\section{Sequence analysis}

Each cluster of nucleotide sequences was annotated by being searched against GenBank NCBI database [92] with BLAST algorithms. Since amino acid sequences are more useful to detect homology over long periods, the assembled sequences were translated on-line into the correct open reading frames (ORFs) using ORFINDER tool from NCBI [93] and compared to the sequences in the NCBI nr and Swissprot protein databases. Sequences that did not match were further compared against the Genbank nucleotide databases (Blastn).

The signalP algorithm [94] was accessed online to predict the presence of signal peptides. The deduced amino acid sequences of all the proteins identified by nano-LCMS/MS analysis were annotated by searching against Pfam protein families database [95]. Modification, cleavage and functional sites were predicted by the ELM server [96].

For amino acid sequence alignments, sequences were retrieved from NCBI $\mathrm{nr}$ database, aligned with sequences from $C$. inanitus with the program MAFFT version 6.0 [97] and edited with the program Jalview [98]. Alignment refinement was done with Gblocks software (version 0.91b) [99]. Phylogenetic relationships were estimated by Bayesian MCMC analyses using the program MrBayes 3.1.2 [100] available online [101,102]. For each set of aligned sequences, we implemented a mixed model of amino acid substitution, with gammacorrection for heterogeneity rate among residues and correction for invariable residues. Model of protein evolution was selected using ProtTest 2.4 software [103].

\section{Additional material}

\section{Additional file 1: Table of peptide identification. Peptidic sequences obtained from the nano-LC-MS/MS analysis of venom proteins from C. inanitus are shown in blue into the corresponding amino acid sequences encoded by ORFs obtained from the transcriptome analysis of $C$. inanitus venom glands.}

Additional file 2: Amino acid sequence alignment of $\mathrm{Ci}-23 \mathrm{a}$ and the venom protein from $\boldsymbol{C}$. $s p$ near curvimaculatus. The amino acid sequence of the venom protein from C. sp near curvimaculatus was retrieved from GenBank [GenBank:ACI70208.1]. The position of a potential cleavage site for both $\mathrm{N}$-arginine dibasic convertase and subtilisin-like proprotein convertase is boxed in black in the Ci-23a sequence. Red and green arrows indicate the beginning of the predicted signal peptide and mature protein sequences of $\mathrm{Ci}-23 \mathrm{a}$, respectively. Serine residues that potentially serve as glycosaminoglycan attachment sites are indicated by blue triangles under the sequence of the venom protein from C. sp near curvimaculatus. Sequence printed in bold was also obtained by $\mathrm{N}$ terminal sequencing of the Ci-23a protein.

Additional file 3: Amino acid sequence alignment of representative chitinases from different insect species. The sequence of the $\mathrm{Ci}-45$ venom chitinase from $C$. inanitus was aligned with sequences of 
chitinases from the following species: the parasitic wasps C. sp. nea curvimaculatus [GenBank:AAA61639.1], T. nigriceps [GenBank:AAX69085.1] and N. vitripennis [GenBank:NP_001128139.2] and the beetle Monochamus alternatus [GenBank:BAF49605.1]. The four conserved regions are boxed. Black triangles indicate catalytic residues. Locations of the glycosyl hydrolase family 18 and chitin-binding Peritrophin-A (CBM_14) domains are indicated by blue and green lines, respectively. Red and green arrows indicate the beginning of the predicted signal peptide and mature protein sequences of $\mathrm{Ci}-45$, respectively. Sequence printed in bold was also obtained by N-terminal sequencing of the $\mathrm{Ci}-45$ protein.

Additional file 4: Amino acid sequence alignment of Imaginal disc Growth Factors (IDGFs)-like proteins from different insect species. The sequence of the $\mathrm{Ci}-48 \mathrm{~b}$ from $\mathrm{C}$. inanitus was aligned with sequences from the following species: N. vitripennis [GenBank:XP_001599305.1], A. mellifera [GenBank:XP 396769.2] and Manduca sexta [GenBank: ACW82749.1]. The conserved region II is boxed. Triangle indicates a glutamine residue replacing, in these proteins, a glutamic acid residue of functional importance. Location of the glycosyl hydrolase family 18 domain is indicated by a blue line. Red and green arrows indicate the beginning of the predicted signal peptide and mature protein sequences of Ci-48b, respectively. Sequence printed in bold was also obtained by $\mathrm{N}$-terminal sequencing of the $\mathrm{Ci}-48 \mathrm{~b}$ protein.

Additional file 5: Amino acid sequence alignment of $\mathrm{Ci}-23 \mathrm{C}, \mathrm{Ci}-220$ and AD-873. The sequences of the $\mathrm{Ci}-23 \mathrm{C}$ and $\mathrm{Ci}-220$ proteins from $\mathrm{C}$. inanitus were aligned with the sequence of the AD-873 protein from Anopheles darlingi [GenBank:ACl30179.1]. Location of the chitin-binding Peritrophin-A (CBM_14) domains of $\mathrm{Ci}-23 \mathrm{C}$ are indicated by green lines under the alignment. Serine residues that potentially serve as glycosaminoglycan attachment sites are indicated by blue triangles. Red and green arrows indicate the beginning of the predicted signal peptide and mature protein sequences of $\mathrm{Ci}-23 \mathrm{c}$, respectively.

Additional file 6: Partial amino acid sequence alignment of $\mathrm{Ci}-300$ with insect metalloproteases. The sequence of $\mathrm{Ci}-300$ was aligned with sequences of metalloproteases from the following species: $N$. vitripennis [NCBI Reference Sequence:XP 001604431.1] and [NCBI Reference Sequence: NP_001155006.1], P. hypochondriaca [GenBank:CAD21587.1] and E. pennicornis [GenBank:ACF60597.1]. The $\mathrm{Zn}^{2+}$-binding motif of HExxHxxGxxH featuring known metalloproteases' partial alignment is boxed in black.

Additional file 7: Amino acid sequence alignment of $\mathrm{Ci}-40 \mathrm{a}$ with serine protease homologs (SPHs). The partial sequence of $\mathrm{Ci}-40 \mathrm{a}$ was aligned with sequences of SPHs from the following species: A. mellifera [NCBI Reference Sequence:XP_623150.2], C. rubecula [GenBank: AAP49428.1], N. vitripennis [NCBI Reference Sequence:NP_001166254.1] and [NCBI Reference Sequence:NP_001155014.1] and A. aegypti [NCBI Reference Sequence:XP_001661226.1]. The location of the trypsin-like serine protease domain of Ci40a is indicated by a blue line under the alignment.

Additional file 8: Sequence similarities between Ci-48a, Vem17 and $\mathrm{Ci}-80 \mathrm{~b}$ and proteins similar to isoforms of lethal (1) G0193. Sequences similarities were determined by comparing the amino acid sequences of $\mathrm{Ci}-48 \mathrm{a}$, Vem17 and $\mathrm{Ci}-80$ to protein sequences deposited in NCBI nr database using BLASTP algorithm. The percentage of identity and E-value are given for each comparison. E: embryo; n.d.: not determined; n.s.: no significant similarity found (E-value> 1e-04); SG: salivary gland; VG: venom gland.

Additional file 9: Phylogeny of the major superfamilies of Hymenoptera. Family and species names discussed in the present paper are indicated on the right side of the figure. The phylogeny of Hymenoptera shown on the left side of the figure is adapted from [9].

\section{Acknowledgements}

This work was supported by grants from the French Agency for National Research (ANR 09-BLAN-0243-01) and the French GDR 2153, as well as the Swiss National Science Foundation (grant 3100A0-116067 to BL). Many thanks to Dr E. Huguet for her critical reading of the manuscript.

\section{Author details}

'UMR 6035 CNRS, Institut de Recherche sur la Biologie de l'Insecte, Faculté des Sciences et Techniques, Université François-Rabelais, Parc Grandmont 37200 Tours, France. ${ }^{2}$ Institute of Cell Biology, University of Berne, Baltzerstrasse 4, CH-3012 Berne, Switzerland. ${ }^{3}$ Department of Clinical Research, University of Bern, Murtenstrasse 35, CH-3010 Berne, Switzerland. ${ }^{4}$ CEA, DSV, Institut de Génomique, Genoscope, 2 rue Gaston Crémieux, CP5706, 91057 Evry, France. ${ }^{5}$ UMR INRA-UM2 1231, Laboratoire Biologie Intégrative et Virologie des Insectes, Université de Montpellier 2, Place E. Bataillon, CC54, 34095 Montpellier cedex 05, France. ${ }^{6}$ Department of Chemistry and Biochemistry, University of Berne, Freiestrasse 3, CH-3012 Berne, Switzerland. 'UMR INRA (1301)-CNRS (6243)-Université Nice Sophia Antipolis, "Interactions Biotiques et Santé Végétale", Institut Agrobiotech, 400 Route des Chappes, 06903 Sophia Antipolis, France.

\section{Authors' contributions}

BV and SM carried out the CDNA library construction, sequence alignments and annotations, performed the phylogenetic analyses and drafted the manuscript. TR isolated the venom gland RNA and participated in the preparation of venom proteins for sequencing. MK participated in the preparation of venom proteins and their sequence analysis. MH carried out the LC-MS/MS analyses and CID spectral interpretation. JS carried out the Nterminal sequencing. JP coordinated ESTs sequencing and quality controls. FC performed ESTs clustering and assembling. BL coordinated the proteomic study and the extraction of RNA from C. inanitus venom gland. JMD and MP participated in the design and coordination of the transcriptomic study. All authors read and approved the final manuscript.

Received: 5 July 2010 Accepted: 7 December 2010

Published: 7 December 2010

\section{References}

1. Kuhn-Nentwig L: Antimicrobial and cytolytic peptides of venomous arthropods. Cell Mol Life Sci 2003, 60:2651-2668.

2. Hoffman DR: Hymenoptera venom allergens. Clin Rev Allergy Immunol 2006, 30:109-128.

3. Wiese MD, Chataway TK, Davies NW, Milne RW, Brown SGA, Gai W-P, Heddle RJ: Proteomic analysis of Myrmecia pilosula (jack jumper) ant venom. Toxicon 2006, 47:208-217.

4. Kolarich D, Loos A, Léonard R, Mach L, Marzban G, Hemmer W, Altmann F: A proteomic study of the major allergens from yellow jacket venoms. Proteomics 2007, 7:1615-1623.

5. Peiren N, Vanrobaeys F, de Graaf DC, Devreese B, Van Beeumen J, Jacobs FJ: The protein composition of honeybee venom reconsidered by a proteomic approach. Biochim Biophys Acta 2005, 1752:1-5.

6. Padavattan S, Schmidt M, Hoffman DR, Marković-Housley Z: Crystal structure of the major allergen from fire ant venom, Sol i 3. J Mol Biol 2008, 383:178-185

7. de Graaf DC, Aerts M, Danneels E, Devreese B: Bee, wasp and ant venomics pave the way for a component-resolved diagnosis of sting allergy. J Proteomics 2009, 72:145-154.

8. Pennacchio F, Strand MR: Evolution of developmental strategies in parasitic Hymenoptera. Annu Rev Entomol 2006, 51:233-258.

9. Whitfield JB: Phylogenetic insights into the evolution of parasitism in Hymenoptera. Adv Parasitol 2003, 54:69-100

10. Doury $G$, Bigot $Y$, Periquet $G$ : Physiological and biochemical analysis of factors in the female venom gland and larval salivary secretions of the ectoparasitoid wasp Eupelmus orientalis. J Insect Physiol 1997, 43:69-81.

11. Nakamatsu Y, Tanaka T: Venom of ectoparasitoid, Euplectrus sp near plathypenae (Hymenoptera: Eulophidae) regulates the physiological state of Pseudaletia separata (Lepidoptera: Noctuidae) host as a food resource. J Insect Physiol 2003, 49:149-159.

12. Abt M, Rivers DB: Characterization of phenoloxidase activity in venom from the ectoparasitoid Nasonia vitripennis (Walker) (Hymenoptera: Pteromalidae). J Invertebr Pathol 2007, 94:108-118.

13. Beckage NE, Gelman DB: Wasp parasitoid disruption of host development: implications for new biologically based strategies for insect control. Annu Rev Entomol 2004, 49:299-330.

14. Asgari S: Venom proteins from polydnavirus-producing endoparasitoids: their role in host-parasite interactions. Arch Insect Biochem Physiol 2006, 61:146-156. 
15. Asgari S: Endoparasitoid venom proteins as modulators of host immunity and development. In Recent Advances in the Biochemistry, Toxicity, and Mode of Action of Parasitic Wasp Venoms. Edited by: Rivers D, Yoder J. Kerala: Research Signpost; 2007:57-73.

16. Poirié $M$, Carton $Y$, Dubuffet $A$ : Virulence strategies in parasitoid Hymenoptera as an example of adaptive diversity. C R Biol 2009, 332:311-320.

17. Moreau SJM, Huguet E, Drezen JM: Polydnaviruses as tools to deliver wasp virulence factors to impair lepidopteran host immunity. In Insect Infection and Immunity: Evolution, Ecology and Mechanisms. Edited by: Rolff J, Reynolds SE. Oxford: Oxford University Press; 2009:137-158.

18. Soller M, Lanzrein B: Polydnavirus and venom of the egg-larval parasitoid Chelonus inanitus (Braconidae) induce developmental arrest in the prepupa of its host Spodoptera littoralis (Noctuidae). J Insect Physiol 1996, 42:471-481.

19. Zhang G, Schmidt O, Asgari S: A novel venom peptide from an endoparasitoid wasp is required for expression of polydnavirus genes in host hemocytes. J Biol Chem 2004, 279:41580-41585.

20. Asgari S, Zareie R, Zhang G, Schmidt O: Isolation and characterization of a novel venom protein from an endoparasitoid, Cotesia rubecula (Hym: Braconidae). Arch Insect Biochem Physiol 2003, 53:92-100.

21. Asgari S, Zhang G, Zareie R, Schmidt O: A serine proteinase homolog venom protein from an endoparasitoid wasp inhibits melanization of the host hemolymph. Insect Biochem Mol Biol 2003, 33:1017-1024

22. Colinet D, Dubuffet A, Cazes D, Moreau S, Drezen JM, Poirié M: A serpin from the parasitoid wasp Leptopilina boulardi targets the Drosophila phenoloxidase cascade. Dev Comp Immunol 2009, 33:681-689.

23. Labrosse C, Stasiak K, Lesobre J, Grangeia A, Huguet E, Drezen J-M, Poirie M: A RhoGAP protein as a main immune suppressive factor in the Leptopilina boulardi (Hymenoptera, Figitidae)-Drosophila melanogaster interaction. Insect Biochem Mol Biol 2005, 35:93-103.

24. Zhang GM, Schmidt O, Asgari S: A calreticulin-like protein from endoparasitoid venom fluid is involved in host hemocyte inactivation. Dev Comp Immunol 2006, 30:756-764

25. Richards EH, Dani MP: Biochemical isolation of an insect haemocyte antiaggregation protein from the venom of the endoparasitic wasp, Pimpla hypochondriaca, and identification of its gene. J Insect Physiol 2008, 54:1041-1049.

26. Colinet D, Schmitz A, Depoix D, Crochard D, Poirié M: Convergent use of RhoGAP toxins by eukaryotic parasites and bacterial pathogens. PLoS Pathog 2007, 3:e203.

27. Moreau SJM, Guillot S: Advances and prospects on biosynthesis, structures and functions of venom proteins from parasitic wasps. Insect Biochem Molec Biol 2005, 35:1209-1223.

28. de Graaf DC, Aerts M, Brunain M, Desjardins CA, Jacobs FJ, Werren JH, Devreese B: Insights into the venom composition of the ectoparasitoid wasp Nasonia vitripennis from bioinformatic and proteomic studies. Insect Mol Biol 2010, 19(Suppl. 1):11-26.

29. Zhu J-Y, Fang Q, Wang L, Hu C, Ye G-Y: Proteomic analysis of the venom from the endoparasitoid Pteromalus puparum (Hymenoptera: Pteromalidae). Arch Insect Biochem Physiol 2010, 75:28-44

30. Parkinson N, Smith I, Weaver R, Edwards JP: A new form of arthropod phenoloxidase is abundant in venom of the parasitoid wasp Pimpla hypochondriaca. Insect Biochem Mol Biol 2001, 31:57-63.

31. Parkinson NM, Conyers C, Keen JN, MacNicoll AD, Weaver ISR: cDNAs encoding large venom proteins from the parasitoid wasp Pimpla hypochondriaca identified by random sequence analysis. Comp Biochem Physiol C 2003, 134:513-520.

32. Parkinson NM, Conyers C, Keen J, MacNicoll A, Smith I, Audsley N, Weaver RJ: Towards a comprehensive view of the primary structure of venom proteins from the parasitoid wasp Pimpla hypochondriaca. Insect Biochem Mol Biol 2004, 34:565-571.

33. Crawford AM, Brauning R, Smolenski G, Ferguson C, Barton D, Wheeler TT, McCulloch A: The constituents of Microctonus sp. parasitoid venoms. Insect Mol Biol 2008, 17:313-324.

34. Stettler P, Trenczek T, Wyler T, Pfister-Wilhelm R, Lanzrein B: Overview of parasitism associated effects on host haemocytes in larval parasitoids and comparison with effects of the egg-larval parasitoid Chelonus inanitus on its host Spodoptera littoralis. J Insect Physiol 1998, 44:817-831.

35. Kaeslin M, Pfister-Wilhelm R, Lanzrein B: Influence of the parasitoid Chelonus inanitus and its polydnavirus on host nutritional physiology and implications for parasitoid development. J Insect Physiol 2005 51:1330-1339.

36. Grossniklaus-Bürgin C, Pfister-Wilhelm R, Meyer V, Treiblmayr K, Lanzrein B: Physiological and endocrine changes associated with polydnavirus/ venom in the parasitoid host system Chelonus inanitus-Spodoptera littoralis. J Insect Physiol 1998, 44:305-321.

37. Pfister-Wilhelm R, Lanzrein B: Stage dependent influences of polydnaviruses and the parasitoid larva on host ecdysteroids. $J$ Insect Physiol 2009, 55:707-715.

38. Kaeslin M, Reinhard M, Bühler D, Roth T, Pfister-Wilhelm R, Lanzrein B: Venom of the egg-larval parasitoid Chelonus inanitus is a complex mixture and has multiple biological effects. J Insect Physiol 2010, 56:686-694.

39. Jones D, Sawickill G, Wozniak M: Sequence, structure, and expression of a wasp venom protein with a negatively charged signal peptide and a novel repeating internal structure. J Biol Chem 1992, 267:14871-14878.

40. Krishnan A, Nair PN, Jones D: Isolation, cloning, and characterization of new chitinase stored in active form in chitin-lined venom reservoir. J Biol Chem 1994, 269:20971-20976.

41. Wagstaff SC, Harrison RA: Venom gland EST analysis of the saw-scaled viper, Echis ocellatus, reveals novel 91 integrin-binding motifs in venom metalloproteinases and a new group of putative toxins, renin-like aspartic proteases. Gene 2006, 377:21-32.

42. Baek JH, Woo TH, Kim CB, Park JH, Kim H, Lee S, Lee SH: Differential gene expression profiles in the venom gland/sac of Orancistrocerus drewseni (Hymenoptera: Eumidae). Archives Insect Biochem Physiol 2009, 71:205-222.

43. Leluk J, Schmidt J, Jones D: Comparative studies on the protein composition of Hymenopteran venom reservoirs. Toxicon 1989, 27:105-114.

44. Taylor $\mathrm{T}$, Jones $\mathrm{D}$ : Isolation and characterization of the $32.5 \mathrm{kDa}$ protein from the venom of an endoparasitic wasp. Biochim Biophys Acta 1990, 1035:37-43.

45. Kramer KJ, Muthukrishnan S: Insect chitinases: molecular biology and potential use as biopesticides. Insect Biochem Mol Biol 1997, 27:887-900.

46. de la Vega H, Specht CA, Liu Y, Robbins PW: Chitinases are a multi-gene family in Aedes, Anopheles and Drosophila. Insect Mol Biol 1998, 7:233-239.

47. Zhu Q, Arakane Y, Banerjee D, Beeman RW, Kramer KJ, Muthukrishnan S: Domain organization and phylogenetic analysis of the chitinase-like family of proteins in three species of insects. Insect Biochem Mol Biol 2008, 38:452-466.

48. Henrissat B: Classification of chitinases modules. EXS 1999, 87:137-156.

49. Zhang $H$, Huang $X$, Fukamizo T, Muthukrishnan S, Kramer KJ: Site-directed mutagenesis and functional analysis of an active site tryptophan of insect chitinase. Insect Biochem Mol Biol 2002, 32:1477-1488.

50. Wang X, Ding X, Gopalakrishnan B, Morgan TD, Johnson L, White FF, Muthukrishnan S, Kramer KJ: Characterization of a $46 \mathrm{kDa}$ insect chitinase from transgenic tobacco. Insect Biochem Mol Biol 1996, 26:1055-1064.

51. Girard C, Jouanin L: Molecular cloning of a gut-specific chitinase CDNA from the beetle Phaedon cochleariae. Insect Biochem Mol Biol 1999, 29:549-556.

52. Han JH, Lee KS, Li J, Kim I, Je YH, Kim DH, Sohn HD, Jin BR: Cloning and expression of a fat body-specific chitinase cDNA from the spider, Araneus ventricosus. Comp Biochem Physiol B Biochem Mol Biol 2005, 140:427-435.

53. Cônsoli FL, Lewis D, Keeley L, Vinson SB: Characterization of a cDNA encoding a putative chitinase from teratocytes of the endoparasitoid Toxoneuron nigriceps. Entomol Exp Appl 2007, 122:271-278.

54. de F MFernandes-Pedrosa, de LM IJunqueira-de-Azevedo, Gonçalves-deAndrade RM, Kobashi LS, Almeida DD, Ho PL, Tambourgi DV: Transcriptome analysis of Loxosceles laeta (Araneae, Sicariidae) spider venomous gland using expressed sequence tags. BMC Genomics 2008 9:279

55. Chen J, Zhao $L$, Jiang $L$, Meng $E$, Zhang $Y$, Xiong $X$, Liang S: Transcriptome analysis revealed novel possible venom components and cellular processes of the tarantula Chilobrachys jingzhao venom gland. Toxicon 2008, 52:794-806.

56. Fry BG, Roelants K, Champagne DE, Scheib H, Tyndall JDA, King GF, Nevalainen TJ, Norman JA, Lewis RJ, Norton RS, Renjifo C, Rodriguez de la Vega RC: The toxicogenomic multiverse: Convergent recruitment of proteins into animal venoms. Annu Rev Genomics Hum Genet 2009, 10:483-511. 
57. Watanabe $T$, Uchida M, Kobori K, Tanaka H: Site-directed mutagenesis of the Asp-197 and Asp-202 residues in chitinase A1 of Bacillus circulans WL-12. Biosci Biotechnol Biochem 1994, 58:2283-2285.

58. Lu Y, Zen KC, Muthukrishnan S, Kramer KJ: Site-directed mutagenesis and functional analysis of active site acidic amino acid residues D142, D144 and E146 in Manduca sexta (tobacco hornworm) chitinase. Insect Biochem Mol Biol 2002, 32:1369-1382.

59. Varela PF, Llera AS, Mariuzza RA, Tormo J: Crystal structure of imaginal disc growth factor-2. A member of a new family of growth-promoting glycoproteins from Drosophila melanogaster. J Biol Chem 2002, 277:13229-13236.

60. Kanost MR, Zepp MK, Ladendorff NE, Andersson LA: Isolation and characterization of a hemocyte aggregation inhibitor from hemolymph of Manduca sexta larvae. Arch Insect Biochem Physiol 1994, 27:123-136.

61. Calvo E, Pham VM, Marinotti O, Andersen JF, Ribeiro JM: The salivary gland transcriptome of the neotropical malaria vector Anopheles darlingi reveals accelerated evolution of genes relevant to hematophagy. BMC Genomics 2009, 10:57.

62. Albert S, Klaudiny J: The MRJP/YELLOW protein family of Apis mellifera: Identification of new members in the EST library. J Insect Physiol 2004, 50:51-59.

63. Drapeau MD, Albert S, Kucharski R, Prusko C, Maleszka R: Evolution of the Yellow/Major Royal Jelly Protein family and the emergence of social behavior in honey bees. Genome Res 2006, 16:1385-1394.

64. Dani MP, Edwards JP, Richards EH: Hydrolase activity in the venom of the pupal endoparasitic wasp, Pimpla hypochondriaca. Comp Biochem Physiol B Biochem Mol Biol 2005, 141:373-381.

65. Rivers $\mathrm{DB}$, Denlinger DL: Venom-induced alterations in fly lipidmetabolism and its impact on larval development of the ectoparasitoid Nasonia vitripennis (Walker) (Hymenoptera, Pteromalidae). J Invertebr Pathol 1995, 66:104-110.

66. Rawlings ND, Barrett AJ: Evolutionary families of metallopeptidases. Methods Enzymol 1995, 248:183-228.

67. Parkinson N, Conyers C, Smith I: A venom protein from the endoparasitoid wasp Pimpla hypochondriaca is similar to snake venom reprolysin-type metalloproteases. J Invertebr Pathol 2002, 79:129-131.

68. Price DR, Bell HA, Hinchliffe G, Fitches E, Weaver R, Gatehouse JA: A venom metalloproteinase from the parasitic wasp Eulophus pennicornis is toxic towards its host, tomato moth (Lacanobia oleracae). Insect Mol Biol 2009, 18:195-202.

69. Ondetti MA, Cushman DW: Enzymes of the rennin-angiotensin system and their inhibitors. Annu Rev Biochem 1982, 51:283-308

70. Isaac RE, Schoofs L, Williams TA, Corvol P, Veelaert D, Sajid M, Coates D: Toward a role for angiotensin-converting enzyme in insects. Ann N Y Acad Sci 1998, 839:288-292.

71. Macours N, Hens K: Zinc-metalloproteases in insects: ACE and ECE. Insect Biochem Mol Biol 2004, 34:501-510.

72. Isaac RE, Bland ND, Shirras AD: Neuropeptidases and the metabolic inactivation of insect neuropeptides. Gen Comp Endocrinol 2009, 162:8-17.

73. Dani MP, Richards EH, Isaac RE, Edwards JP: Antibacterial and proteolytic activity in venom from the endoparasitic wasp Pimpla hypochondriaca (Hymenoptera: Ichneumonidae). J Insect Physiol 2003, 49:945-954

74. Serbielle C, Moreau S, Veillard F, Voldoire E, Mannucci M-A, Volkoff A-N, Drezen J-M, Lalmanach G, Huquet E: Identification of parasite-responsive cysteine proteases in Manduca sexta. Biol Chem 2009, 390:493-502.

75. Lee S, Nalini M, Kim Y: A viral lectin encoded in Cotesia plutellae bracovirus and its immunosuppressive effect on host hemocytes. Comp Biochem Physiol Part A Mol Integr Physiol 2008, 149:351-361.

76. Forêt S, Wanner KW, Maleszka R: Chemosensory proteins in the honey bee: Insights from the annotated genome, comparative analyses and expressional profiling. Insect Biochem Mol Biol 2007, 37:19-28.

77. Tegoni M, Campanacci V, Cambillau C: Structural aspects of sexual attraction and chemical communication in insects. Trends Biochem Sci 2004, 29:257-264.

78. Xu YL, He P, Zhang L, Fang SQ, Dong SL, Zhang YJ, Li F: Large-scale identification of odorant-binding proteins and chemosensory proteins from expressed sequence tags in insects. BMC Genomics 2009, 10:632.

79. Gmachl M, Kreil G: Bee venom hyaluronidase is homologous to a membrane protein of mammalian sperm. Proc Natl Acad Sci USA 1993, 90:3569-3573.
80. Lu G, Villalba M, Coscia MR, Hoffman DR, King TP: Sequence analysis and antigenic cross-reactivity of a venom allergen, antigen 5 , from hornets, wasps, and yellow jackets. J Immunol 1993, 150:2823-2830.

81. Fang KSY, Vitale M, Fehlner P, King TP: CDNA cloning and primary structure of a white-face hornet venom allergen, antigen 5. Proc Natl Acad Sci USA 1988, 85:895-899.

82. Bézier A, Annaheim M, Herbinière J, Wetterwald C, Gyapay G, BernardSamain S, Wincker P, Roditi I, Heller M, Belghazi M, Pfister-Wilhem R, Periquet G, Dupuy C, Huguet E, Volkoff AN, Lanzrein B, Drezen JM: Polydnaviruses of braconid wasps derive from an ancestral nudivirus. Science 2009, 323:926-930.

83. Kaeslin M, Wehrle I, Grossnikluas-Bürgin C, Wyler T, Guggisberg U, Schittny JC, Lanzrein B: Stage-dependent strategies of host invasion in the egg-larval parasitoid Chelonus inanitus. J Insect Physiol 2005, 51:287-296.

84. Grimaldi D, Engel MS: Evolution of the insects New York: Cambridge University Press; 2005.

85. The Nasonia Genome Working Group, et al: Functional and evolutionary insights from the genomes of three parasitoid Nasonia species. Science 2010, 327:343-348

86. Johner A, Lanzrein B: Characterization of two genes of the polydnavirus of Chelonus inanitus and their stage-specific expression in the host Spodoptera littoralis. J Gen Virol 2002, 83:1075-1085.

87. Johner A, Stettler P, Gruber A, Lanzrein B: Presence of polydnavirus transcripts in an egg-larval parasitoid and its lepidopterous host. J Gen Virol 1999, 80:1847-1854.

88. Pertea G, Huang $X$, Liang F, Antonescu V, Sultana R, Karamycheva S, Lee $Y$, White J, Cheung F, Parvizi B, Tsai J, Quackenbush J: TIGR Gene Indices clustering tools (TGICL): a software system for fast clustering of large EST datasets. Bioinformatics 2003, 19:651-652.

89. Huang X, Madan A: CAP3: A DNA sequence assembly program. Genome Res 1999, 9:868-877.

90. Gene Ontology Consortium: The Gene Ontology (GO) project in 2006. Nucleic Acids Res 2006, , 34 Database: D322-D326.

91. Conesa A, Götz S, García-Gómez JM, Terol J, Talón M, Robles M: Blast2GO: A universal tool for annotation, visualization and analysis in functional genomics research. Bioinformatics 2005, 21:3674-3676.

92. Basic Local Alignment Search Tool. [http://www.ncbi.nlm.nih.gov/blast]

93. ORF Finder. [http://www.ncbi.nlm.nih.gov/projects/gorf/]

94. SignalP 3.0 Server. [http://www.cbs.dtu.dk/services/SignalP]

95. Pfam 24.0 home page. [http://pfam.sanger.ac.uk]].

96. ELM server. [http://elm.eu.org/]

97. Katoh K, Misawa K, Kuma K, Miyata T: MAFFT: a novel method for rapid multiple sequence alignment based on fast Fourier transform. Nucleic Acid Res 2002, 30:3059-3066.

98. Clamp M, Cuff J, Searle SM, Barton GJ: The Jalview Java alignment editor. Bioinformatics 2004, 20:426-427.

99. Castresana J: Selection of conserved blocks from multiple alignments for their use in phylogenetic analysis. Mol Biol Evol 2000, 17:540-552.

100. Ronquist F, Huelsenbeck JP: MrBayes3: Bayesian phylogenetic inference under mixed models. Bioinformatics 2003, 19:1572-1574.

101. Phylogeny.fr: Home. [http://www.phylogeny.fr].

102. Dereeper A, Guignon V, Blanc G, Audic S, Buffet S, Chevenet F, Dufayard JF, Guindon S, Lefort V, Lescot M, Claverie JM, Gascuel O: Phylogeny.fr: robust phylogenetic analysis for the non-specialist. Nucleic Acids Res 2008, 36:465-469.

103. Abascal F, Zardoya R, Posada D: ProtTest: Selection of best-fit models of protein evolution. Bioinformatics 2005, 21:2104-2105.

doi:10.1186/1471-2164-11-693

Cite this article as: Vincent et al: The venom composition of the parasitic wasp Chelonus inanitus resolved by combined expressed sequence tags analysis and proteomic approach. BMC Genomics 2010 11:693. 